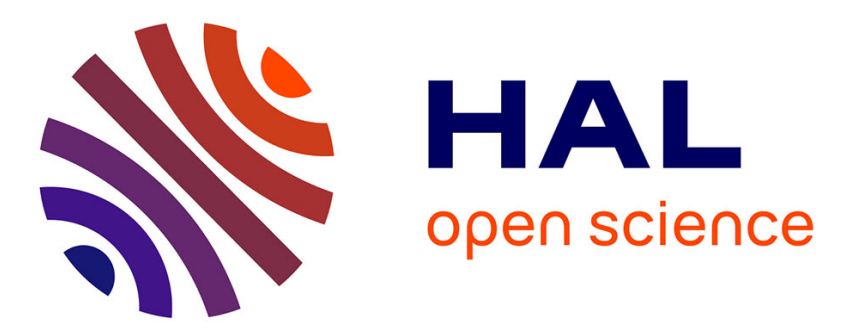

\title{
NEXAFS Studies on the Surface Structure of Liquid n-C50H102 (Pentacontane)
}

\author{
Y. Yamamoto, R. Mitsumoto, T. Araki, Y. Ouchi, H. Ishii, K. Seki, N. Ueno, \\ Y. Takanishi
}

\section{- To cite this version:}

Y. Yamamoto, R. Mitsumoto, T. Araki, Y. Ouchi, H. Ishii, et al.. NEXAFS Studies on the Surface Structure of Liquid n-C50H102 (Pentacontane). Journal de Physique IV Proceedings, 1997, 7 (C2), pp.C2-709-C2-710. 10.1051/jp4:1997214 . jpa-00255201

\section{HAL Id: jpa-00255201 https://hal.science/jpa-00255201}

Submitted on 1 Jan 1997

HAL is a multi-disciplinary open access archive for the deposit and dissemination of scientific research documents, whether they are published or not. The documents may come from teaching and research institutions in France or abroad, or from public or private research centers.
L'archive ouverte pluridisciplinaire HAL, est destinée au dépôt et à la diffusion de documents scientifiques de niveau recherche, publiés ou non, émanant des établissements d'enseignement et de recherche français ou étrangers, des laboratoires publics ou privés. 


\title{
NEXAFS Studies on the Surface Structure of Liquid $n-C_{50} \mathbf{H}_{102}$ (Pentacontane)
}

\author{
Y. Yamamoto, R. Mitsumoto, T. Araki, Y. Ouchi, H. Ishii, K. Seki, N. Ueno* and Y. Takanishi** \\ Department of Chemistry, Nagoya University, Chikusa-ku, Nagoya 464-01, Japan \\ * Department of Materials Science, Chiba University, Inage-ku, Chiba 263, Japan \\ ** Department of Organic and Polymeric Materials, Tokyo Institute of Technology, Tokyo 152, Japan
}

\begin{abstract}
The surface freezing effect of $n$-alkane has been studied by Near Edge X-ray Absorption Fine Structure (NEXAFS) spectroscopy. Samples used in the experiment were $n-\mathrm{C}_{50} \mathrm{H}_{102}$ (pentacontane) $2500 \AA$ thick films evaporated on $\mathrm{Cu}$ substrate. An ordered structure has been observed at a $1.3^{\circ} \mathrm{C}$ higher temperature than the bulk melting point. Angle resolved measurement has revealed that the molecular long axis of pentacontane in the surface freezing layer is almost perpendicular to the surface.
\end{abstract}

\section{INTRODUCTION}

Surface structures of $n$-alkanes have been the subject of recent interest since the discovery of a surface freezing effect, where the surface freezing refers to the phenomena that a thin layer at an air/substance interface freezes first from an isotropic (or liquid) phase at a higher temperature than the bulk melting point. Wu et al[1] have observed the phenomena of the $n$-alkanes with use of grazing incidence $X$-ray diffraction technique, and have concluded that the thickness of the layer corresponds to almost a full molecular length. Later, Sefler et al[2] have applied a Sum Frequency Generation technique to obtain more microscopic pictures of the system, such as a direction of end methyl group. Although several other related papers[3] have been published so far, experimental evidences and detailed understandings are still lacking.

In this study, we will report an experimental study of the surface freezing effect with use of Near Edge X-ray Absorption Fine Structure (NEXAFS) spectroscopy[4]. NEXAFS has been recognized as a convenient tool to study the orientation of adsorbates on a solid surface. By virtue of the short escape depth of a photoelectron, the technique has also been applied to the study of the surface structure of polymer and/or oligomer thin films [5,6]. Since UHV environment for NEXAFS measurement is not suited to the liquid system because of its higher vapor pressure, we have properly selected the sample $\left(n-\mathrm{C}_{50} \mathrm{H}_{102}\right.$ : pentacontane) in order to overcome such difficulties. It has been found that the surface of pentacontane has a higher melting point, indicating that the surface frizzing layer exist at the air/pentacontane interface. Angle resolved measurement has revealed that the molecule in the surface-freezing-layer aligns almost perpendicularly to the surface.

\section{EXPERIMENTAL}

$n-\mathrm{C}_{50} \mathrm{H}_{102}$ (pentacontane) was purchased from SIGMA Co., and used without any further purification. The sample film was prepared on $\mathrm{Cu}$ substrate by vacuum evaporation. The thickness was monitored by quartz oscillator to be $2500 \AA$. We have confirmed that the pentacontane film in the liquid phase completely wet the $\mathrm{Cu}$ substrate surface in a separate experiment, indicating that our NEXAFS experiment has truly observed the liquid surface of pentacontane. C K-edge NEXAFS spectra were measured at the BL-11A of Photon Factory at National Laboratory for High Energy Physics (KEK-PF) with a Grasshopper monochromator (2400 lines $/ \mathrm{mm}$ ). Measurements were performed in the total-electron yield mode under the vacuum of $10^{-8}$ Torr range. In order to investigate the orientation of molecules, we examined the incident angle dependence of the spectra.

\section{RESULT AND DISCUSSION}

Figure 1 is a typical example of C K-edge NEXAFS spectra for normal incidence (NI: $\theta=90^{\circ}$ ) and grazing incidence (GI: $\theta=$ $\left.20^{\circ}\right)$ cases at various temperatures. Peaks (a) $(287.8 \mathrm{eV})$ and (b) $(293.4 \mathrm{eV})$ have already been assigned as $\mathrm{C} 1 \mathrm{~s} \rightarrow \sigma *(\mathrm{C}-\mathrm{H})$ and $\sigma *$ (C-C) resonances, respectively[6]. The molecules in the film initially aligned parallel to the substrate surface and gradually changed their orientation with the increase of the temperature. In order to detect the surface freezing layer, we fixed the energy of incident photon at $287.8 \mathrm{eV}(\sigma *(\mathrm{C}-\mathrm{H})$ resonance) and observed an intensity variation of the $\sigma *(\mathrm{C}-\mathrm{H})$ peak while changing the temperature at the rate of $\pm 0.1^{\circ} \mathrm{C} / \mathrm{min}$. Results are summarized in Figure 2 . In the first heating process (1), the peak intensity slightly changed at the bulk melting point $\left(95.5^{\circ} \mathrm{C}\right)$ indicated by an arrow. With further increase of temperature, the intensity does not change. At almost 1.3 degree above the melting point, the intensity suddenly and then gradually decreased until $97.5^{\circ} \mathrm{C}$ where we have already confirmed the surface has an isotropic liquid structure as is clear from Fig.1. In the subsequent cooling process (1'), the intensity suddenly jumped up at $96.5^{\circ} \mathrm{C}$ and then gradually increased up to $94.6^{\circ} \mathrm{C}$. In the second (2) and third(3) cycle of the heating and cooling processes, the intensity variation relative to the temperature was more or less the same. Above the bulk melting point, the $\sigma *(\mathrm{C}-\mathrm{H})$ peak intensity varies with the increase of the temperature, indicating that an ordered structure at the surface of liquid pentacontane may exist. 
In order to elucidate the molecular orientation of the ordered structure at the surface, we carried out an angle resolved NEXAFS measurement at a carefully fixed temperature A indicated in Fig. 2. The spectra obtained are summarized in Figure 3. Peak intensity variation of $\sigma *(\mathrm{C}-\mathrm{H})$ resonance relative to the incident angle of light indicates that the molecular axis is almost perpendicular to the surface. As compared to the results of highly oriented $n-\mathrm{C}_{36} \mathrm{H}_{72}$ films[6], however, the variation of the peak intensity is less pronounced, suggesting that the surface freezing layer may have a certain degree of disorder.

\section{CONCLUSION}

With use of NEXAFS spectroscopy, we have successfully observed the surface freezing layer of the $n$ $\mathrm{C}_{50} \mathrm{H}_{102}$ (pentacontane). The molecular orientation in the layer is found to be almost perpendicular to the surface.

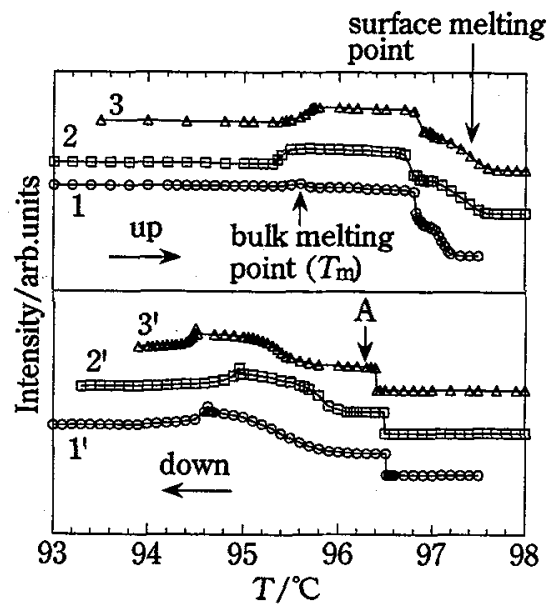

Figure 2 : The temperature variation of $\sigma *(\mathrm{C}-\mathrm{H})$ peak intensity of $n-\mathrm{C}_{50} \mathrm{H}_{102}$, Above the bulk melting point shown by an arrow, peak intensity variation has still been observed, suggesting that an ordered layer may exist on the liquid $n-\mathrm{C}_{50} \mathrm{H}_{102}$ surface.

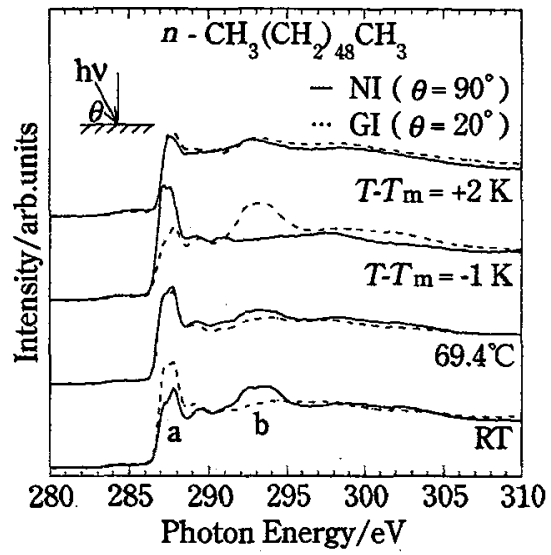

Figure 1 : C K-edge NEXAFS spectra of $n$ - $\mathrm{C}_{50} \mathrm{H}_{102}$ $2500 \AA$ thick film taken at various temperatures. Peaks (a) and (b) are assigned as $\sigma *(\mathrm{C}-\mathrm{H})$ and $\sigma *(\mathrm{C}-\mathrm{C})$ resonances, respectively.

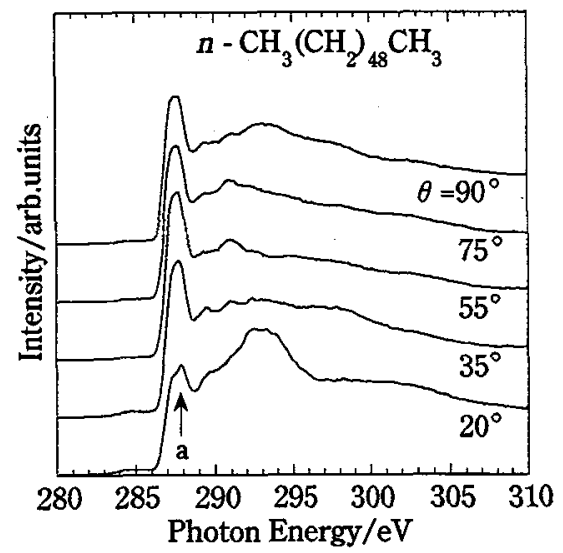

Figure 3: C K-edge NEXAFS spectra of the surface freezing layer of $n-\mathrm{C}_{50} \mathrm{H}_{102}$ taken at $\mathrm{A}$ in Fig. 2. The intensity of the peak (a) is much larger at $\theta=90^{\circ}$ than at $\theta$ $=20^{\circ}$. indicating qualitatively that the molecular long axes are almost perpendicular to the surface.

\section{Acknowledgments}

The authors are grateful to Prof. A. Yagishita, and Dr. T. Kitajima of KEK-PF for experimental help. This work was partly supported by the Grant-in-Aid for Scientific Research by the Ministry of Education, Science, Sports, and Culture of Japan (Nos. 07NP0303, 07CE2004, \& 08CE2004) and by the Venture Business Laboratory Program of Nagoya University. This work was performed under the approval of the Photon Factory Programs Advisory Committee (Nos. 93G318, 93G324, 95G372 and 95G374).

\section{References}

[1]Wu X.Z., Sirota E. B., Sinha S. K., Ocko B. M. and Deutch M., Phys. Rey. Lett. 70 (1993) 953 - 961.

[2]Sefler G. A., Du Q., Miranda P. B., Shen Y. R., Chem. Phys. Lett. 235 (1995) 347 - 354.

[3]Tkachenko A. V. and Rabin Y., Phys. Rev. Lett. 76 (1996) $2527-2530$

[4]Stöhr J., NEXAFS Spectroscopy (Springer-Verlag, Berlín, 1992).

[5]Yamamoto Y., Mitsumoto R., Ito E., Araki T., Ouchi Y., Seki K. and Takanishi Y., J. Electron Spectrsc. 78 (1996) 367

[6]Ohta T., Seki K., Yokoyama T., Morisada I. and Edamatsu K., Physica Scripta, 41 (1990) 150. 